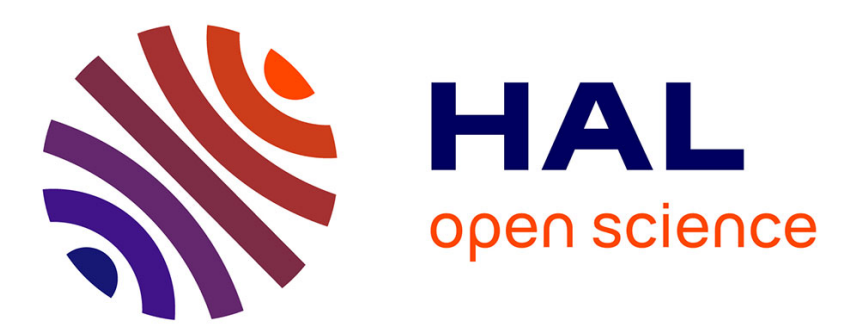

\title{
A Long-Term Effect of Perceptual Individuation Training on Reducing Implicit Racial Bias in Preschool Children
}

Miao Qian, Paul C. Quinn, Gail D. Heyman, Olivier Pascalis, Genyue Fu, Kang Lee

\section{To cite this version:}

Miao Qian, Paul C. Quinn, Gail D. Heyman, Olivier Pascalis, Genyue Fu, et al.. A Long-Term Effect of Perceptual Individuation Training on Reducing Implicit Racial Bias in Preschool Children. Child Development, 2017, 90 (3), pp.e290-e305. 10.1111/cdev.12971 . hal-01618303

\section{HAL Id: hal-01618303 https://hal.science/hal-01618303}

Submitted on 7 May 2020

HAL is a multi-disciplinary open access archive for the deposit and dissemination of scientific research documents, whether they are published or not. The documents may come from teaching and research institutions in France or abroad, or from public or private research centers.
L'archive ouverte pluridisciplinaire HAL, est destinée au dépôt et à la diffusion de documents scientifiques de niveau recherche, publiés ou non, émanant des établissements d'enseignement et de recherche français ou étrangers, des laboratoires publics ou privés. 


\title{
A Long-Term Effect of Perceptual Individuation Training on Reducing Implicit Racial Bias in Preschool Children
}

\author{
Miao K. Qian \\ Hangzhou Normal University and University of Toronto \\ Gail D. Heyman \\ University of California, San Diego and Zhejiang Normal \\ University \\ Genyue Fu \\ Hangzhou Normal University
}

\author{
Paul C. Quinn \\ University of Delaware
}

\author{
Olivier Pascalis \\ Université de Grenoble Alpes
}

Kang Lee
University of Toronto and Zhejiang Normal University

\begin{abstract}
This study tracked the long-term effect of perceptual individuation training on reducing 5-year-old Chinese children's $\left(N=95, M_{\text {age }}=5.64\right.$ years $)$ implicit pro-Asian/anti-Black racial bias. Initial training to individuate other-race Black faces, followed by supplementary training occurring 1 week later, resulted in a long-term reduction of pro-Asian/anti-Black bias (70 days). In contrast, training Chinese children to recognize White or Asian faces had no effect on pro-Asian/anti-Black bias. Theoretically, the finding that individuation training can have a long-term effect on reducing implicit racial bias in preschoolers suggests that a developmentally early causal linkage between perceptual and social processing of faces is not a transitory phenomenon. Practically, the data point to an effective intervention method for reducing implicit racism in young children.
\end{abstract}

Our increasingly globalized world offers opportunities for positive interactions with people from different cultural backgrounds. However, it also poses challenges as diverse groups of individuals representing various cultures, religious beliefs, and customs learn to live and work together. One such major challenge is racism. In the present research, we focus on how to reduce one form it can take: implicit racial bias. This type of bias refers to unconscious stereotypes, prejudices, and discriminatory behaviors based on race. Like the more consciously accessible forms of explicit racial bias, implicit racial bias develops in early childhood between 3 and 6 years of age (Baron \& Banaji, 2006; Dunham, Baron, \& Banaji, 2006; Dunham, Chen, \& Banaji, 2013; Qian et al., 2016, 2017; Raabe \& Beelmann, 2011; Xiao et al., 2015), if not earlier

This research was supported by grants from the National Natural Science Foundation of China (31771227, 31371041, and 31470993), the National Institutes of Health (R01 HD046526), and the Natural Science and Engineering Research Council of Canada (NSERC).

Correspondence concerning this article should be addressed to Genyue Fu, Department of Psychology, Hangzhou Normal University. No. 2318 Yuhangtang Road, Hangzhou 31121, China or Kang Lee, Dr. Eric Jackman Institute of Child Study, University of Toronto, 45 Walmer Road, Toronto, Ontario M5R 2X2, Canada. Electronic mails may be sent to fugy@zjnu.cn or kang.lee@utoronto.ca.
(Quinn et al., 2013; Xiao, Quinn, et al., 2017; Xiao, $\mathrm{Wu}$, et al., 2017).

Implicit racial bias in adults is automatic, ubiquitous, and pernicious (Dovidio, Kawakami, \& Gaertner, 2002; Dunham, Baron, \& Banaji, 2008; Greenwald \& Banaji, 1995). It has far-reaching negative personal and societal consequences in all spheres of human life, including education, health care, employment, justice, finance, politics, and even dating (Hardin \& Banaji, 2013; Pearson, Dovidio, \& Gaertner, 2009). Although researchers have tried many approaches to reduce implicit racial bias in adults, studies that examine long-term changes in implicit racial bias are rare and suggest that effects of bias reduction are at best short lived (Lai et al., 2014, 2016). One reason for the limited effectiveness of existing approaches is that by adulthood, implicit racial bias is highly consolidated and resistant to change (Bigler, 2013; Bigler \& Liben, 2007; Dunham et al., 2008). Thus, to reduce racial bias effectively with lasting effects, one needs to do so in childhood before it becomes entrenched (Lai et al., 2016).

(C) 2017 The Authors

Child Development (C) 2017 Society for Research in Child Development, Inc. All rights reserved. 0009-3920/2017/xxxx-xxxx

DOI: $10.1111 /$ cdev. 12971 


\section{Qian et al.}

For decades there were no reliable ways to measure implicit racial bias in children, and consequently, antiracism educational efforts in childhood have almost exclusively targeted explicit racial bias (Aboud et al., 2012; Bigler, 2013; Hitti \& Killen, 2015; Rutland, Hitti, Mulvey, Abrams, \& Killen, 2015). Recent methodological innovations in measuring implicit bias (Baron \& Banaji, 2006; Cvencek, Greenwald, \& Meltzoff, 2011, 2016; Dunham, Baron, \& Carey, 2011; Dunham et al., 2006; Dunham et al., 2013; Qian et al., 2016, 2017; Xiao et al., 2015) now make it possible to systematically investigate how to reduce it early in life.

Several recent studies have shown that one novel approach has at least immediate implicit racial bias reduction effects in both children and adults. This approach involves perceptual individuation training in which participants learn to distinguish between different individuals of another race. Lebrecht, Pierce, Tarr, and Tanaka (2009) trained adults to recognize the identities of other-race faces (individuation) or classify them by race (categorization). They found that an intensive 45-min-long individuation training produced an immediate reduction of implicit racial bias against the trained other race, whereas categorization training did not. Xiao et al. (2015) examined whether individuation training might also be effective in reducing implicit racial bias in young children. They tested this possibility with an angry = out-group paradigm (Dunham et al., 2011; Hugenberg \& Bodenhausen, 2004). Initially, Chinese children between 4 and 6 years were biased to classify angry racially ambiguous faces as Black and happy racially ambiguous faces as Chinese, but the bias was eliminated with training to individuate other-race Black faces (see also Qian et al., 2017). The findings not only confirmed the viability of using individuation training to reduce children's implicit racial bias, but also supported the contention that intervention in childhood may be more effective than in adulthood.

Why should individuation training be effective in reducing implicit racial bias? A recently proposed perceptual-social linkage hypothesis (Lee, Quinn, \& Heyman, 2017; Lee, Quinn, \& Pascalis, 2017; Quinn et al., 2013) provides a plausible explanation. Lee, Quinn, and colleagues contend that in infancy and early childhood, most children have greater exposure to individual own-race faces than to other-race ones. This early asymmetry in own- versus other-race face experience is known to have perceptual consequences. For example, as early as in infancy, other-race members are perceived as more homogenous than those within one's own-race group (out-group homogeneity: Linville, Fischer, \& Salovey, 1989; for a review of the relevant developmental work, see Anzures et al., 2013). Relatedly, infants and young children respond to other-race faces by their race category, rather than individuate them (Dunham, Stepanova, Dotsch, \& Todorov, 2015; Quinn, Lee, Pascalis, \& Tanaka, 2016).

The perceptual-social linkage hypothesis further contends that the early asymmetry in exposure to own- versus other-race faces will have not only perceptual consequences in terms of face recognition and categorization, but also social consequences in terms of racial bias. Specifically, the exposure disparity leads infants to come to differentially associate positive or negative valence with own- versus otherrace faces. This is because infants are typically exposed to own-race individuals who interact with them positively (Kim \& Johnson, 2014; Malatesta \& Haviland, 1982; Trainor, Austin, \& Desjardins, 2000). As a result, infants may respond positively to ownrace individuals relative to other-race individuals (i.e., in-group favoritism: Tajfel \& Turner, 1979; Turner \& Reynolds, 2010). In contrast, the propensity of infants to be wary of novel stimuli in general and strangers in particular (Bigelow, MacLean, Wood, \& Smith, 1990; Bronson, 1972; Campos, Emde, Gaensbauer, \& Henderson, 1975), and the perceptual differences between familiar own-race faces and unfamiliar other-race faces, may lead infants to respond more negatively to unfamiliar other-race individuals relative to own-race individuals (Tajfel \& Turner, 1979; Turner \& Reynolds, 2010). Recent findings are consistent with this contention. For example, Xiao, Quinn, et al. (2017) found that between 6 and 9 months of age, infants began to associate own-race faces with happy music and other-race faces with sad music. In addition, Xiao, Wu, et al. (2017) reported that 7-month-old infants learned to follow eye gaze cues from own-race adults more readily than from other-race adults.

From the perspective of the perceptual-social linkage hypothesis, individuation training on otherrace faces is effective in reducing implicit racial bias because it provides experience with other-race faces. More specifically, individuation training reduces homogeneity of out-group members and interrupts the tendency to lump those faces together by their racial category. As a collateral consequence, the association of negative valence with unfamiliar other-race faces is disrupted, leading to the reduction of racial bias.

Although the findings from the two existing studies on perceptual individuation training are 
consistent with the perceptual-social linkage hypothesis (Lebrecht et al., 2009; Xiao et al., 2015), it is possible that these effects reflect only temporary disruptions to, rather than fundamental breakdowns of, the association between other race and negative attitudes formed in early development. If true, it would suggest that the perceptual-social linkage seen in the previous studies is an ephemeral phenomenon. In contrast, evidence that individuation training has a long-lasting effect would suggest a more fundamental change in implicit racial bias and thus provide stronger support for the perceptual-social linkage hypothesis. Such evidence would also lay an important empirical foundation for the development of an effective intervention method in reducing implicit racial bias in childhood.

The present study used a pre- and posttest design to examine the potential long-term effectiveness of perceptual individuation training. We recruited Chinese preschool children from China. These children live in a racially homogeneous environment (e.g., with $99.9 \%$ of the population being Han Chinese), and have been found to harbor robust implicit racial bias against other-race individuals (Qian et al., 2016, study 1). Specifically, Chinese preschool-age children showed an implicit bias against Black individuals $(D=.42)$ and against White individuals $(D=.16)$. We targeted Chinese children with no direct contact with any other-race individuals to control for the potential confound of direct other-race contact preand posttraining. Consequently, this sample allowed us to test specifically whether individuation training could indeed lead to a long-lasting reduction in children's implicit racial bias.

Chinese children's implicit racial bias was measured by the implicit racial bias test (IRBT; Qian et al., 2016). Following more traditional measures of implicit racial bias (e.g., Cvencek, Greenwald, et al., 2011; Greenwald, Nosek, \& Banaji, 2003), our IRBT assesses children's implicit racial bias as a whole, without separating implicit pro-own-race bias from anti-other-race bias. Thus, henceforth, we will refer to such bias as implicit pro-Asian/antiBlack bias. After pretesting Chinese children's implicit pro-Asian/anti-Black bias, we randomly assigned them to either an experimental training procedure or to one of two control conditions. The experimental condition, which was expected to reduce implicit pro-Asian/anti-Black bias, involved a Black individuation condition in which children were briefly trained to recognize individual Black faces. One control condition involved learning to individuate other-race White faces (the other-race
White individuation condition), and the other involved learning to individuate own-race Asian faces (the own-race Asian individuation condition). The Asian individuation control condition was included to rule out the possibility that any training effect in the experimental Black individuation condition was due to individuation training per se regardless of whether children were trained to recognize own- or other-race faces. The White individuation control condition was included to ascertain whether any training effect in the experimental Black individuation condition was specific to the race of faces being trained or generalizable to faces belonging to a nontrained other-race category. For all three conditions, we posttested participants multiple times after training to assess implicit proAsian/anti-Black bias over the course of 70 days.

It should be noted that prior training studies have mostly produced immediate effects in reducing implicit bias in children and adults. The few studies that examined longer term effects of training only included adults. They revealed that significant bias reduction effects, if they indeed existed, lasted for a few days at best (Dasgupta \& Greenwald, 2001; Lai et al., 2016; Marini, Rubichi, \& Sartori, 2012; Olson \& Fazio, 2006; but see Devine, Forscher, Austin, \& Cox, 2012). Several reasons might account for the lack of long-term effects. First, as mentioned earlier, implicit bias in adults could be so entrenched that training might be able to disturb the bias temporarily, but unable to alter it permanently. This reasoning would suggest that children might be more likely to manifest longer term effects of training. However, to our knowledge, no such study has examined the long-term effects of implicit racial bias reduction manipulations in children.

Second, the existing training methods might not be long or intensive enough to create long-term effects. Supporting this claim, Devine et al. (2012) used an intensive and multifaceted training program with adults. Their bias reduction program produced a reduction in implicit bias that lasted 8 weeks. However, follow-up studies with larger samples failed to replicate this finding, suggesting that simply making interventions longer and more intensive may not be sufficient for long-term change (Lai et al., 2016). Third, interventions could be effective if they are administered with repetition over time in a spaced learning schedule (Greene, 1990; Hintzman \& Block, 1973). No study has ever examined this possibility.

Recognizing this significant gap in the literature, to maximize a potential long-term effect of training, 


\section{Qian et al.}

we not only tested a large sample of children, but also included both an initial training session and a supplementary training session. The additional training was identical to the first training and was performed 1 week after the initial training. We then tracked the effects of the initial and supplementary training over a 10-week period (70 days; see Figure 1). Although our intervention targeted implicit bias, we also included measures of explicit bias in order to further examine the specificity of our effects. Based on previous research showing no relation between implicit and explicit racial biases (Qian et al., 2016), we expected that any effects of the training would be specific to implicit bias.

We hypothesized that, consistent with previous findings, Chinese children would show an immediate reduction in implicit pro-Asian/anti-Black bias in the experimental condition where they learned to distinguish between different Black individuals (Lebrecht et al., 2009; Xiao et al., 2015). However, whether this effect would extend over a longer term period was an open question. We also hypothesized that individuation training with Asian faces would have no effect because such training is working in concert with extensive past experience. With regard to the White individuation training, one possibility would be that individuation training for one other-

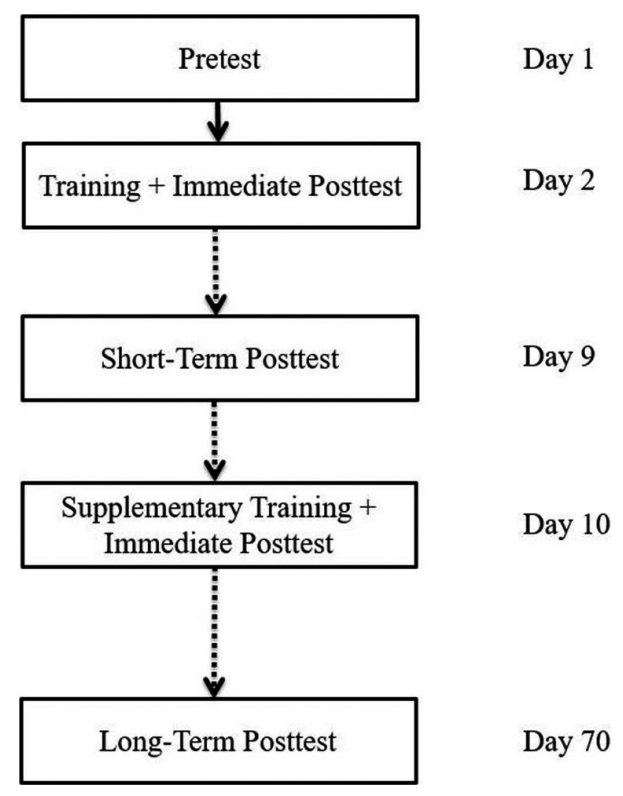

Figure 1. Timing of bias assessments. Children's implicit and explicit pro-Asian/anti-Black biases were assessed at five time points: before and immediately after individuation training, 9 days after pretest, 10 days after pretest, and 70 days after pretest. race face category produces a generalized effect whereby it not only reduces implicit bias for ownrace and against the trained other-race category, but also reduces implicit bias against another untrained other-race category. If this possibility is true, we would expect the White individuation training condition to reduce implicit pro-Asian/ anti-Black bias. Alternatively, if individuation training only produces a specific effect that is limited to the trained face category, we would expect no reduction in implicit pro-Asian/anti-Black bias in the White individuation condition.

\section{Method \\ Participants}

The sample consisted of 95 Chinese kindergarten children from an eastern city in China (47 males, 48 females), $M_{\text {age }}=5.65$ years, $S D=.69$. Data were collected between March 2015 and September 2015. Participants were all Han Chinese, which represents $99.9 \%$ of the local population, from families of all walks of life (median parental education level was Grade 12). The study was approved by the university research ethics committee. Informed consent was obtained from all parents or legal guardians prior to the beginning of the study and oral assent was obtained from all child participants. According to reports from the children's parents or legal guardians, none of the children had direct interaction with any non-Asian individuals before their participation in the research.

As in most longitudinal studies, there was some attrition. Nine participants were excluded on Day 2 because of failure to complete the individuation training. Two participants were excluded on Day 9 because they were unavailable for testing. Eight participants were excluded on Day 10: 5 due to failure to complete the supplementary training and 3 were not available for testing. Twenty-four participants were excluded on Day 70: 22 because they had left the kindergarten and 2 because they were unavailable for testing. The total number of participants contributing data at each of the testing time points is shown in Figure 4.

\section{Materials and Procedures}

Participants were tested individually in a quiet room at their kindergarten. A female Chinese graduate student tested all participants using Mandarin. We used a pre- and posttest design, with participants being assessed for pro-Asian/anti-Black bias 
at both pretest and multiple posttests (see Figure 1 for information about the timing of the bias assessments).

\section{Pretest Measure of Implicit Bias}

To measure implicit pro-Asian/anti-Black bias, we used the IRBT at pretest. The IRBT is a preschooler-friendly implicit association test (IAT) adapted from Cvencek, Greenwald, et al. (2011). This test measures positive and negative associations with own versus other race by looking at associations between faces of different races, and positive versus negative attributes that are represented by smiling or frowning faces. Similar to the IAT for adults, the logic here is that if participants differ in their response time to smiling or frowning faces paired with either own-race Asian faces or other-race Black faces, then this outcome provides evidence of bias.

Unlike the prior IAT, the IRBT only requires participants to learn one set of associations at a time and respond with intuitively labeled buttons on a touch screen. In addition, the IRBT reduces the lexical processing demand by including only pictorial stimuli, thereby helping to rule out language-specific effects (Danziger \& Ward, 2010), and eliminating the need to read any materials. These adaptations make it more appropriate for young children, and are similar to what other researchers have done to examine implicit association among young children (Cvencek, Meltzoff, \& Greenwald, 2011; Thomas, Burton Smith, \& Ball, 2007). The error rate of the IRBT is low $(<10 \%)$ and effect size is typically large (Cohen's $d=.40)$. These indices attest to the effectiveness and appropriateness of the IRBT for assessing implicit racial bias among young children. Also, the IRBT has been cross validated in both Africa and China by yielding effects that are consistent with prior research (Qian et al., 2016). That is, using the same face stimuli belonging to different races (Caucasian, African, and Asian), Asian preschoolers showed implicit bias in favor of Asians but against Caucasians and Africans, whereas African preschoolers showed implicit bias in favor of Africans but against Caucasians and Asians.

The IRBT was conducted on a Microsoft Surface Pro with a touch screen, using E-prime 2.0 (Psychology Software Tools, Sharpsburg, PA). The stimuli consisted of color photos of 20 Asian faces (10 females and 10 males) and 20 Black faces (10 females and 10 males). All faces were chosen from an existing face database (Ge et al., 2009), standardized at 480 pixels $(17 \mathrm{~cm})$ wide and 600 pixels
$(21 \mathrm{~cm})$ high, and had a resolution of 72 pixels per in. The face images were frontal view without obvious marks such as beards, glasses, or facial makeup. These faces were chosen according to the results of a rating experiment in which all faces in the database were rated on attractiveness and distinctiveness by 20 Chinese adults who did not participate in the current study. We only selected White, Black, and Asian faces that were rated similarly by Chinese adults, and perceived to be in the average range (within $1 S D$ of the mean) on the dimensions of attractiveness and distinctiveness. All faces were overlaid with the same elliptical shape so that hair was not visible.

Participants viewed Black faces and Asian faces and were instructed to touch either the smile or frown symbol when they saw a face of a particular race (see Figure 2). For "congruent" pairings, participants were told to touch the smile symbol when they saw an Asian face and to touch the frown symbol when they saw a Black face. In contrast, for "incongruent" pairings, they were told to touch the frown symbol when they saw an Asian face and to touch the smile symbol when they saw a Black face. A practice block of eight trials was included before testing to familiarize children with instructions in both "congruent" and "incongruent" blocks.

We used the standard $D$ score to measure implicit racial bias as in previous research (Greenwald et al., 2003). The $D$ score is the difference between the average responses latencies between contrasted pairings divided by standard deviation of response latencies across the pairings (Greenwald, McGhee, \& Schwartz, 1998; Greenwald et al., 2003). The D score measured by the IRBT reflects in-group preference and out-group dislike concurrently, given how it is calculated as below in Equations 1a and $1 b$.

$$
\begin{aligned}
& D=\frac{\left[\mathrm{RT}_{\text {incongruent }}-\mathrm{RT}_{\text {congruent }}\right]}{S D} \\
& \begin{array}{c}
{\left[\mathrm{RT}_{(\text {own-race }=\text { sad \& other-race }=\text { happy })}\right.} \\
=\frac{\left.-\mathrm{RT}_{(\text {own }- \text { race }=\text { happy \& other }- \text { race }=\text { sad })}\right]}{S D}
\end{array} \\
& {\left[\left(\mathrm{RT}_{\text {own-race }}=\text { sad }-\mathrm{RT}_{\text {own-race }}=\text { happy }\right)\right.}
\end{aligned}
$$

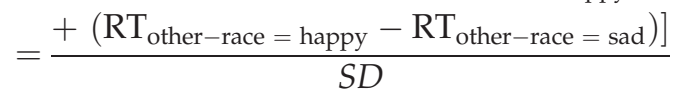

Thus, for Chinese participants, a $D$ score above 0 indicates that they concurrently have an implicit pro-Asian/anti-Black bias. 

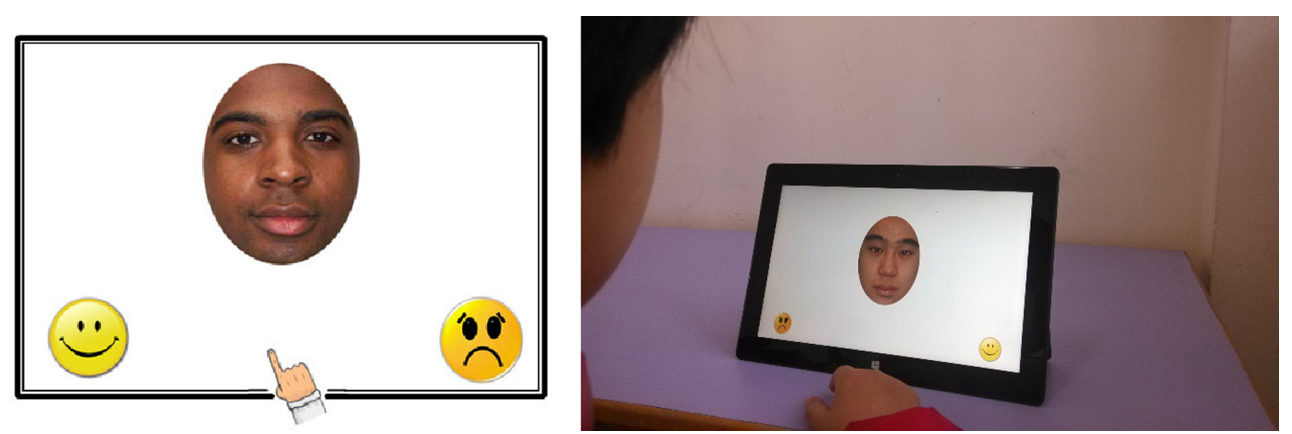

Figure 2. The participant's view of the screen for the Asian-Black implicit racial bias test. On "congruent" pairings, participants were told to touch a smile when they saw an own-race Asian face and to touch a frown when they saw an other-race Black face. On "incongruent" pairings, they were told to touch a frown when they saw an own-race Asian face and to touch a smile when they saw an other-race Black face.

\section{Perceptual Individuation Training}

After assessing the pro-Asian/anti-Black bias of participants at pretest, they were assigned to one of three possible training groups in a between-subjects design. The first one was a Black individuation experimental condition in which participants learned to individuate between faces in the racial group targeted for reduction: Black faces. The second and third groups were control conditions involving the same form of training on races other than the group targeted for reduction. Specifically, one involved learning to individuate between ingroup members (Asian), and the other involved learning to individuate between members of another out-group (Caucasian). Assignment to one of the three groups was done based on pretest scores to insure that individuals assigned to each of the groups started out with similar levels of implicit pro-Asian/anti-Black bias. This was accomplished by arranging the pretest scores from lowest to highest. Individuals with the closest $D$ scores were grouped into sets of three, and individuals within each of these sets were randomly assigned to the three conditions.

The training procedure was the same as in Xiao et al. (2015) with each session lasting for about $20 \mathrm{~min}$. In the Black individuation training condition, the stimuli consisted of five color photos of Black males between 20 and 35 years of age. The stimuli in the other conditions were selected according to the same requirements except that faces in the White individuation training group were color photos of White males and the faces in the Asian individuation training group were color photos of Asian males. Across all conditions, individuation training consisted of learning the identity of these five same-race faces and involved associating numbers between 1 and 5 to each face (see Figure 3 as an example).

Individuation training began with a two-face training block in which children were asked to remember two faces and their corresponding numbers (e.g., "1" and "2"). Children then completed a naming task, during which two faces from the learning task were randomly displayed, with the numbers from 1 to 5 presented underneath the faces as response options. Children responded by touching on the number that was associated with each learned face. Feedback was given after each

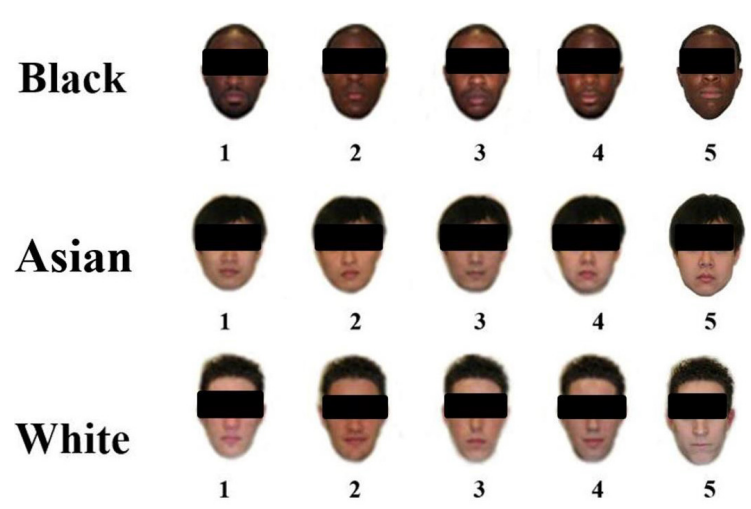

\section{Individuation Training}

Figure 3. Perceptual individuation training procedure. In the Black individuation condition, children learned to associate five individual Black faces with five individual numbers. In the Asian individuation condition, children learned to associate five individual Asian faces with five individual numbers. In the White individuation condition, children learned to associate five individual White faces with five individual numbers. We have included a black bar on each face to conceal the identities of the individuals whose faces were used as stimuli. In the actual training and testing, however, each face was presented without a black bar. 
response. After correctly individuating two faces, they were asked to do a three-face training block in which a new face was added along with a new corresponding number (e.g., "3"). Children were then asked to do the same learning and naming training as in the two-face training block. Four-face training and five-face training were exactly the same except that one new face along with a new corresponding number was added in each block. Thus, to proceed to the next block, children had to label the faces with 100\% accuracy; otherwise, the block was repeated until they reached $100 \%$ accuracy. Training stopped when all five faces were learned and labeled with corresponding numbers correctly. We used numbers instead of African or Asian names when teaching children to individuate the Black faces because African names would sound highly unfamiliar to Chinese children, as would associating Asian names with African individuals. The training face photos were different from those used in the IRBT or explicit choice task (see following). All faces from a given race had a similar hairstyle and exhibited neutral expressions (see Figure 3). Images $(600 \times 480$ pixels $)$ were presented on a Microsoft Surface Pro Tablet (17-in. display screen).

\section{Posttests of Implicit Bias and Their Timing}

Regardless of condition, all participants took part in pro-Asian/anti-Black implicit bias assessments on five occasions (see Figure 1 for the timeline). We pretested children's implicit pro-Asian/ anti-Black bias on Day 1 and posttested their implicit pro-Asian/anti-Black bias immediately after individuation training on Day 2. Seven days after Day 2 on Day 9, we assessed children's implicit pro-Asian/anti-Black bias again. One day later on Day 10, we administered a second Black individuation training as supplementary training and immediately posttested children's implicit proAsian/anti-Black bias. As mentioned earlier, because the existing training studies have shown that the training effects of implicit racial bias reduction, if any exist, tend to last for just a few days (Lai et al., 2016; Olson \& Fazio, 2006), we planned this supplementary training session to examine whether repeated training would maximize a potential long-term effect. The supplementary training was identical to the first training with the same individual faces in each condition. On Day 70, which was 60 days after the supplementary training, we again assessed children's implicit bias.

\section{Measures of Explicit Bias and Their Timing}

Children's explicit racial bias was assessed using the choice task at the same time points in which implicit biases were assessed. The choice task was modeled after Kinzler, Shutts, DeJesus, and Spelke (2009; see also Baron \& Banaji, 2006; Dunham et al., 2006; Qian et al., 2016). On the choice task, children were asked about their preference when interacting with an Asian individual or a Black individual in four different contexts (e.g., This summer, your mother will take you on vacation. On your trip, you can choose one person as your travel guide. Which one would you like to choose, the Asian or the Black?). Children's preference for the Asian adult over Black adult was coded as 1 and their preference for the Black adult over Asian adult was coded as 0 in each of the four scenarios. The scores were added up and divided by 4 to derive a proportion score, with .50 as the no-bias score.

The implicit measures were always presented first because these were of greatest theoretical interest and because prior research suggests that there are no order effects on these measures (Nosek, Greenwald, \& Banaji, 2007).

\section{Results}

Consistent with procedures from previous IAT studies with adults (Greenwald et al., 2003) and children (Cvencek, Greenwald, et al., 2011), data were excluded from participants on the basis of three criteria: (a) $\geq 10 \%$ of responses faster than $300 \mathrm{~ms},(\mathrm{~b}) \geq$ error rate of $30 \%$, or (c) average response latency $3 S D$ above the mean response latency for the whole sample. These criteria excluded two children due to excessive errors, leaving 93 children for analysis. Preliminary analyses revealed no significant effect of sex, $t(91)=0.59$, $p=.557$. Thus, the data were combined for this factor in subsequent analyses.

\section{Implicit Racial Bias}

The mean scores and standard errors of the three training groups are shown in Figure 4.

\section{Immediate Effect of Initial Training}

To examine the immediate effect of individuation training on reducing implicit pro-Asian/anti-Black bias, we conducted a repeated measures analysis of variance (ANOVA) with training condition (Black 


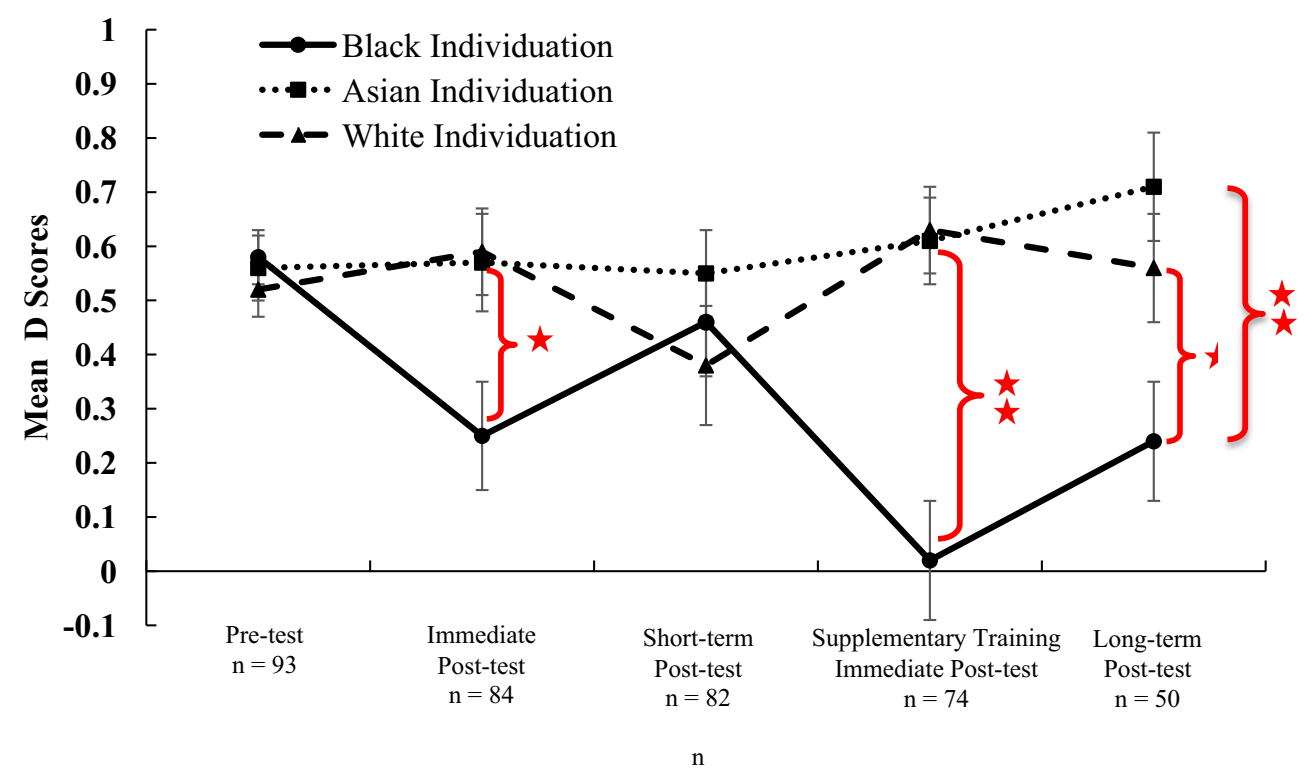

Figure 4. Implicit pro-Asian/anti-Black biases among the three individuation training groups. A positive value of $D$ indicates a preference for Asian relative to Black. A score of zero represents no bias. Error bars represent standard errors. One star denotes $p<.05$ and two stars denote $p<.01$.

individuation, Chinese individuation, and White individuation) as a between-subjects variable and time (pretest and immediate posttest) as a repeated measures variable. We found a significant interaction between time and training condition, $F(2,81)=2.99, p=.029, \eta_{p}^{2}=.08$. To further assess the effects in each training group, we performed a one-way repeated measures ANOVA for the three training groups separately. For the Black training group, we found a significant time effect, $F(1$, $29)=6.71, p=.015, \eta_{p}^{2}=.19$, showing a significant decrease in implicit pro-Asian/anti-Black bias between pretest $(D=.58, S E=.05)$ and immediate posttest after individuation training $(D=.25$, $S E=.12)$. This result indicates that Black individuation training reduced Chinese children's implicit pro-Asian/anti-Black bias. However, we did not find any significant time effects for either the Chinese individuation training group, $F(1,26)=0.03$, $p=.857, \eta_{\mathrm{p}}^{2}=.001$, or White individuation training group, $F(1,26)=0.58, p=.455, \eta_{p}^{2}=.02$, meaning that Chinese and White individuation trainings did not reduce Chinese children's implicit pro-Asian/ anti-Black bias.

To examine the difference between the three training groups in their implicit pro-Asian/antiBlack bias, we then performed a one-way ANOVA. Although there was no significant difference in implicit pro-Asian/anti-Black bias among the three training groups at pretest, $F(2,90)=0.31, p=.738$, there was a significant difference at immediate posttest, $F(2,81)=3.68, p=.030$. These results show that Black individuation training significantly reduced Chinese children's implicit pro-Asian/antiBlack bias, while Asian and White individuation trainings did not.

To examine whether individuation training eliminated children's implicit pro-Asian/anti-Black bias, we performed one-sample $t$ tests to compare each training group's mean $D$ score against zero (no bias). This analysis revealed that the three training groups showed implicit pro-Asian/anti-Black bias at pretest, all ts $>9.13$ and $p s<.001$. It also revealed that after the initial training, the Black individuation training group still showed significant implicit pro-Asian/anti-Black bias at immediate posttest, $t(29)=2.11, p=.043$, which suggested that the individuation training of Black faces reduced but did not eliminate children's pro-Asian/ anti-Black implicit bias. At immediate posttest, both Asian and White individuation training groups continued to show implicit pro-Asian/anti-Black bias, all $t \mathrm{~s}>5.52$ and $p$ s $<.001$.

The analyses collectively suggest that Black individuation training reduced, but did not eliminate children's pro-Asian/anti-Black bias. By contrast, neither Asian nor White individuation training affected their pro-Asian/anti-Black bias. 


\section{Short-Term Effect 1 Week After Initial Training}

To examine the short-term effect of Black individuation training after 1 week, we conducted a repeated measures ANOVA with time (pretest and short-term posttest) as a within-subjects variable. We did not find a significant time effect in the Black individuation training group, $F(1,28)=1.36$, $p=.253, \eta_{\mathrm{p}}^{2}=.05$. These results indicate that Black individuation training did not yield a short-term training effect on reducing implicit pro-Asian/antiBlack bias 1 week after training. We also performed one-sample $t$ tests to compare each training group's mean $D$ score at short-term posttest against zero (no bias). This analysis revealed that the three training groups showed reliable implicit pro-Asian/antiBlack bias at short-term posttest, all ts $>3.38$ and $p s<.002$. These results taken together indicate that Chinese children from each of the three training groups showed an implicit pro-Asian/anti-Black bias 1 week after training.

\section{Immediate Effect of Supplementary Training}

To examine the immediate effect of the supplementary individuation training, we conducted a repeated measures ANOVA with training condition as a between-subjects variable (Black individuation, Asian individuation, and White individuation) and time (pretest, supplementary training immediate posttest) as a repeated measures variable. We found a significant interaction between time and training condition, $F(2,71)=13.48, p<.001, \eta_{p}^{2}=.28$. To further examine the effect of time in each group, we performed a one-way repeated measures ANOVA for each training group. For the Black individuation training group, we found a significant effect of time, $F(1,28)=24.60, p<.001$, $\eta_{\mathrm{p}}^{2}=.47$. This result revealed that supplementary Black individuation training had an immediate effect on reducing Chinese children's implicit pro-Asian/anti-Black bias. However, we did not find any significant effect for either the Asian individuation training group or White individuation training group, all $F_{\mathrm{s}}<1.03$ and $p \mathrm{~s}>.216$, indicating that neither Asian nor White supplementary individuation training had an effect on children's implicit pro-Asian/anti-Black bias.

To test the difference between the three training groups in their implicit pro-Asian/anti-Black bias at immediate posttest after supplementary training, we conducted a one-way ANOVA. It revealed a significant difference in implicit pro-Asian/antiBlack bias among the three training groups at immediate posttest, $F(2,71)=13.82, p<.001$. Post hoc testing (least significant difference test [LSD]) revealed a significant difference between the Black individuation training condition $(D=.02, S E=.11)$ and Asian individuation training condition $(D=.61, S E=.08), p<.001,95 \% \mathrm{CI}=[-.86,-.32]$, and between the Black individuation training condition and White individuation training condition $(D=.63, S E=.08), p<.001,95 \% \mathrm{CI}=[-.86,-.34]$. This pattern of outcomes indicates that the Black individuation supplementary training produced a significant immediate effect in reducing children's implicit pro-Asian/anti-Black bias, but the Asian and White individuation supplementary trainings did not.

To further examine whether supplementary training eliminated children's implicit pro-Asian/ anti-Black bias at immediate posttest, we performed a one-sample $t$ test. We compared each training group's mean $D$ score at immediate posttest against zero (no bias). This analysis revealed that the Black individuation training group showed no implicit pro-Asian/anti-Black bias at immediate posttest, $t$ $(28)=0.23, p=.823$, whereas the Asian and White individuation training groups showed implicit proAsian/anti-Black bias, all ts $>7.66$ and $p s<.001$. These outcomes indicate that supplementary Black individuation training eliminated children's implicit pro-Asian/anti-Black bias at immediate posttest, but the Asian and White individuation trainings did not.

\section{Long-Term Effect of Supplementary Training}

To examine the long-term effect of supplementary training, we conducted a repeated measures ANOVA with training condition as a between-subjects variable (Black individuation, Chinese individuation, and White individuation) and time (pretest, long-term posttest) as a repeated measures variable. We found a significant interaction between training condition and time, $F(2,47)=3.86, p=.028$, $\eta_{\mathrm{p}}^{2}=.14$. To further examine the effect of time in each group, we performed a one-way repeated measures ANOVA for each training group, separately. For the Black individuation training group, we found a significant effect for time, $F(1,14)=8.20, p=.013, \eta_{p}^{2}=.37$. This result indicates that supplementary Black individuation training had a long-term effect reducing Chinese children's implicit pro-Asian/anti-Black bias. However, we did not find any long-term effect for either the Asian individuation or White individuation training group, all $F \mathrm{~s}<0.36$ and $p \mathrm{~s}>.559$. 
To examine the difference in long-term effects between the three training groups in their implicit pro-Asian/anti-Black bias, we performed a one-way ANOVA. It revealed a significant difference in implicit pro-Asian/anti-Black bias among the three training groups at long-term posttest, $F(2,47)=$ $5.12, p=.010$. Post hoc testing (LSD) revealed a significant difference between the Black individuation training condition $(D=.24, S E=.10)$ and Asian individuation training condition $(D=.71, S E=.10)$, $p=.003,95 \% \mathrm{CI}=[-.78,-.17]$, and between the Black individuation training condition and White individuation training condition $(D=.56, S E=.10)$, $p=.028,95 \% \mathrm{CI}=[-.62,-.04]$. These results indicate that the supplementary Black individuation training had a long-term effect on reducing implicit bias of at least 70 days. In contrast, the Asian and White individuation trainings did not show any long-term effects.

To further examine whether supplementary training eliminated children's implicit pro-Asian/ anti-Black bias at long-term posttest, we performed one-sample $t$ tests. We compared each training group's mean $D$ score at long-term posttest against zero (no bias). This analysis revealed that the Black individuation training group still showed implicit pro-Asian/anti-Black bias at long-term posttest, $t(14)=2.18, p=.047$, and that the Asian and White individuation training groups also showed implicit pro-Asian/anti-Black bias, all ts $>5.53$ and ps $<.001$.

The combined findings from the different analyses of the long-term effects of the supplementary training indicate that although the supplementary training was not able to retain the eliminative effect on pro-Asian/anti-Black bias that was present in the initial aftermath of the supplementary training, it did produce a long-term training effect in reducing children's implicit pro-Asian/anti-Black bias that lasted for at least 70 days. In contrast, supplementary Asian and White individuation trainings did not impact children's implicit pro-Asian/antiBlack bias.

\section{Explicit Racial Bias}

The mean scores and standard errors of each training group are shown in Figure 5. To examine immediate, short-term, and long-term training effects, we performed the same analyses that were used to examine explicit pro-Asian/anti-Black bias. They revealed that Black individuation training, Asian individuation training, and White individuation training did not have an immediate, short-term, or long-term training effect on reducing children's explicit pro-Asian/anti-Black bias, all Fs $<1.54$ and $p s>.213$.

\section{Discussion}

The present study examined the long-term effect of perceptual individuation training on reducing children's implicit pro-Asian/anti-Black bias. We trained 4- to 6-year-old Chinese children to individuate Black faces, Asian faces, and White faces, and

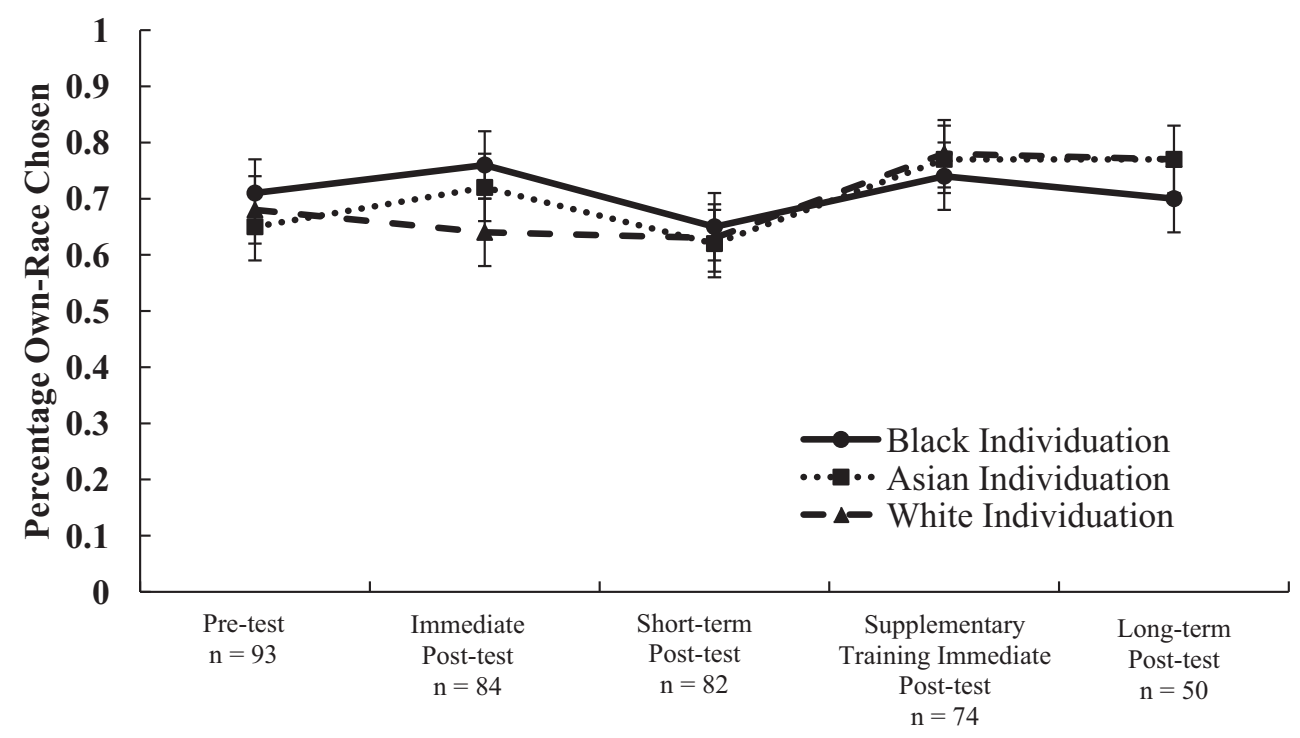

Figure 5. Explicit pro-Asian/anti-Black bias among the three individuation training groups. A score $>.50$ indicates a preference for Asian relative to Black. A score of .50 indicates no bias. Error bars represent standard errors. 
tracked their implicit pro-Asian/anti-Black bias for 70 days. We obtained three major findings. First, training Chinese preschoolers to individuate otherrace Black faces, unlike training them to individuate own-race Asian faces or other-race White faces, resulted in an immediate reduction in implicit proAsian/anti-Black bias. Second, the combination of initial and supplementary training involving individuation of other-race Black, but not own-race Asian faces or other-race White faces, resulted in a long-term reduction in implicit pro-Asian/antiBlack bias. Third, the individuation training effect was specific to reducing implicit, but not explicit, racial bias.

The result that Chinese children's implicit proAsian/anti-Black bias was significantly reduced immediately after Black face individuation training is consistent with recent studies demonstrating effectiveness of individuation training for reducing implicit racial bias within a short time span after training (Lebrecht et al., 2009; Xiao et al., 2015). Taken together, the present and prior findings suggest that individuation skills learned on faces of a given race can extend to novel exemplars of the trained race (Lebrecht et al., 2009; McGugin, Tanaka, Lebrecht, Tarr, \& Gauthier, 2011). Our data also extend previous work with children by showing that the immediate effect of perceptual individuation training with other-race faces is specific to the race group targeted in training, which is consistent with the results of the adult training studies (Lebrecht et al., 2009; McGugin et al., 2011).

Most importantly, unlike Xiao et al. (2015) and Lebrecht et al. (2009) who only tested immediate training effects, we for the first time investigated both short- and long-term effects of individuation training. We found that one session of individuation training, while producing an immediate effect, failed to have a lasting effect: 1 week after the training, children's implicit racial bias returned to the pretraining level. These results are consistent with previous findings with adults that most interventions immediately reduce implicit racial bias, but fail to sustain the effect after a delay of several days (Lai et al., 2016). However, we showed that with one additional supplemental individuation training session, bias reduction lasted for at least 70 days. Overall, our results suggest that supplementary training in combination with initial training, but not supplementary training alone, contributed to the long-term effect of individuation training.

Our findings provide support for the perceptualsocial linkage hypothesis (Lee, Quinn, \& Heyman,
2017; Lee, Quinn, \& Pascalis, 2017; Quinn et al., 2013). As mentioned earlier, this hypothesis posits that implicit racial bias in favor of own-race faces and against other-race faces is a social consequence of children's differential processing experience of own-race versus other-race faces. Specifically, this hypothesis suggests that the early emergence of implicit bias results from two early tendencies: the tendency to categorize other-race faces and the tendency to form relatively more positive associations with individuals from familiar categories. Individuation training disrupts children's tendency to categorize other-race faces by race. This in turn decreases the likelihood that attitudes and stereotypes, which are mostly negative (Banaji \& Greenwald, 2013), will be applied to members of the other-race category.

The present findings along with those by Xiao et al. (2015) support the idea that there is a causal relation between children's perceptual processing of other-race faces and implicit racial bias against them. By teaching children to recognize the faces of individuals of one other race, we significantly reduced their racial bias with long-lasting effect. Also, the fact that our individuation training of White faces did not lead to a reduction of children's anti-Black implicit racial bias points to the specificity of our causal effect.

The present findings also have important practical implications. First, they point to the need for early exposure to other-race faces. If implicit racial bias is a social consequence of early differential exposure to own- versus other-race faces as contended by the perceptual-social linkage hypothesis, then early intervention to increase exposure to other-race faces should help reduce implicit racial bias in children. However, mere exposure is not likely to be sufficient. Rather, other-race faces may need to be individuated, as suggested by the present and previous studies (Lebrecht et al., 2009; Qian et al., 2017; Xiao et al., 2015). Furthermore, as the differential exposure to own- versus other-race faces begins in infancy, our findings suggest that such intervention may have maximum benefit when begun early in life.

Second, it has been suggested that to reduce racial bias effectively, one of the best approaches is to engage individuals in immersive and prolonged interaction with other-race individuals (Neto, da Conceiçao Pinto, \& Mullet, 2016; Pettigrew \& Tropp, 2006; Rudman, Ashmore, \& Gary, 2001; Shook \& Fazio, 2008). However, it might not be possible for young children to have such opportunities, especially for those living in homogeneous 
racial settings (e.g., in most parts of Asia and Africa, and some parts of the United States, that have no or very few other-race individuals). Even in multicultural and multiracial settings, young children may have only limited opportunities to interact with other-race children due to school and community segregation (Glazerman \& Dotter, 2016). Our findings suggest that direct interactions with other-race individuals might not be necessary to reduce implicit racial bias with lasting effects. Rather, training children to recognize images of other-race individuals may be sufficient to obtain a long-term reduction in implicit racial bias. Thus, the findings suggest that individuation training may be an efficient and effective intervention strategy that is applicable to a wide range of settings.

Third, most of the existing intervention studies have produced immediate or short-term effects that at best lasted only several days in reducing adult racial bias (see Lai et al., 2016 for a review). These studies raise doubts about the long-term viability of such intervention in reducing implicit racial bias. However, our data indicate that it is indeed possible to achieve a long-lasting effect in children before biases become entrenched. Furthermore, our findings suggest that training that engages the process of perceptual individuation can be simple and brief as long as it is administered in multiple sessions. As mentioned earlier, the best training effect to date was achieved with the use of an intensive and multifaceted training program (Devine et al., 2012), which reduced implicit racial bias for a duration of 8 weeks. Unfortunately, because this intervention included an intensive learning procedure, which lasted for $45 \mathrm{~min}$, it might not be appropriate for young children due to their limited attention span. In contrast, our approach offers a short and childfriendly intervention that takes about $20 \mathrm{~min}$ to complete. Moreover, given the fact that our training sessions were successfully delivered on a touch screen computer, the program can be readily adapted for use in a more game-like fashion on smartphones or Pads.

Although the present study is the first to demonstrate the long-term viability of perceptual individuation training in reducing young children's implicit racial bias, many questions still need to be answered. For example, dosage and timing are factors that can contribute to the effectiveness of any training. Both of these will need to be systematically manipulated in future research to optimize the effectiveness of individuation training. In addition, given that the bias was reduced but not eliminated in the immediate posttest after initial training and in the long-term posttest after supplementary training, it will be important to assess whether it is possible to improve its effectiveness. For example, it will be important to examine the effects of having more training trials in a single session or more training sessions with fewer trials, and to investigate changes in the timing of the supplemental training. It will also be informative to determine whether training children to individuate Black females, instead of Black males, would reduce antiBlack bias. Furthermore, the present study involved children who had no direct contact with other-race individuals, so it will also be valuable to examine children with such contact, as well as biracial children, in addition to examining possible effects of indirect contact with other races, inclusive of media exposure. Such studies could help delineate the role of prior exposure in the effectiveness of individuation training on implicit racial bias reduction. Additional studies are also needed to measure children's executive function and to control for the possibility of immature executive function on the IRBT (Ito et al., 2015). Finally, the present study used an implicit racial bias measure that concurrently measures children's pro-own-race and anti-other-race implicit bias. It is therefore unclear whether individuation training reduces either children's pro-ownrace bias or their anti-other-race bias or both. Future research using measures capable of separating these effects will be needed to clarify this issue.

It should be noted that the effect of perceptual individuation training was specific to implicit racial bias, as was evident by the lack of any effect on explicit bias. These results are consistent with previous findings that implicit racial bias is unrelated to explicit racial bias in children even though children show both implicit and explicit racial biases (Baron \& Banaji, 2006; Dunham et al., 2006; Qian et al., 2016). In addition, adult training studies have consistently shown that whereas training sometimes reduces implicit racial bias, the same training had little impact on explicit racial bias (Lai et al., 2014, 2016). Nevertheless, one source of the lack of correlation between implicit and explicit racial bias measures and the related null effect of training in reducing children's explicit racial bias may be the explicit measure used. In the present study and those prior investigations that have measured children's implicit and explicit racial bias concurrently, an explicit choice or preference task was used. One issue that needs to be addressed in future studies is why children show preferences for own-race individuals on such tasks. It is possible that these preferences reflect greater familiarity with own-race 
individuals (Zebrowitz, Bronstad, \& Lee, 2007) or assumptions about parental expectations. Further studies with additional explicit racial bias measures will be needed to distinguish between these possibilities.

Methodological issues notwithstanding, it is also possible that children's implicit and explicit racial biases are indeed unrelated because implicit and explicit biases have different developmental origins. Implicit bias may stem from early perceptual experience individuating own- but not other-race faces. In contrast, explicit bias may be learned from social experience (e.g., social learning from adults and peers). If this is the case, then different strategies may be needed to reduce the two types of biases: perceptual means to reduce implicit bias and social means to reduce explicit bias (Gawronski \& Bodenhausen, 2006; Pettigrew \& Tropp, 2006). In addition, it is possible that intergroup contact quantity is associated with more positive implicit bias, whereas intergroup contact quality is associated with positive explicit bias (Prestwich, Kenworthy, Wilson, \& Kwan-Tat, 2008). For this reason, individuation training may be sufficient to reduce children's implicit racial bias but not their explicit racial bias. As proposed by Allport (1979), further characteristics that facilitate contact quality such as intergroup cooperation may be necessary to improve explicit attitudes toward other-race members. This suggestion raises the possibility of increasing other-race contact quality to directly reduce explicit racial bias and thereby indirectly reduce implicit racial bias, an idea that awaits confirmation with specifically designed studies.

In summary, we have shown that individuation training can effectively reduce implicit racial bias and that this effect is specific to the race group targeted at training. More importantly, we for the first time documented that individuation training can be effective for at least 70 days. Our findings support the perceptual-social linkage hypothesis by providing evidence for a causal linkage between children's perceptual experience with faces and implicit racial bias. From a practical standpoint, our findings point to a potentially effective and efficient intervention strategy to counter implicit racial bias in early childhood with long-lasting effect.

\section{References}

Aboud, F. E., Tredoux, C., Tropp, L. R., Brown, C. S., Niens, U., \& Noor, N. M. (2012). Interventions to reduce prejudice and enhance inclusion and respect for ethnic differences in early childhood: A systematic review. Developmental Review, 32, 307-336. https://doi. org/10.1016/j.dr.2012.05.001

Allport, G. W. (1979). The nature of prejudice. New York, NY: Basic Books.

Anzures, G., Quinn, P. C., Pascalis, O., Slater, A. M., Tanaka, J. W., \& Lee, K. (2013). Developmental origins of the other-race effect. Current Directions in Psychological Science, 22, 173-178. https://doi.org/10.1177/ 0963721412474459

Banaji, M., \& Greenwald, A. (2013). Blindspot: Hidden biases of good people. New York, NY: Delacorte Press.

Baron, A. S., \& Banaji, M. R. (2006). The development of implicit attitudes: Evidence of race evaluations from ages 6 and 10 and adulthood. Psychological Science, 17, 53-58. https://doi.org/10.1111/j.1467-9280.2005.01664.x

Bigelow, A., MacLean, J., Wood, C., \& Smith, J. (1990). Infants' responses to child and adult strangers: An investigation of height and facial configuration variables. Infant Behavior and Development, 13, 21-32. https: / / doi.org/10.1016/0163-6383(90)90003-Q

Bigler, R. S. (2013). Understanding and reducing social stereotyping and prejudice among children. In M. R. Banaji \& S. A. Gelman (Eds.), Navigating the social world: What infants, children, and other species can teach us (pp. 327-331). New York, NY: Oxford University Press.

Bigler, R. S., \& Liben, L. S. (2007). Developmental intergroup theory explaining and reducing children's social stereotyping and prejudice. Current Directions in Psychological Science, 16, 162-166. https://doi.org/10.1111/j. 1467-8721.2007.00496.x

Bronson, G. W. (1972). Infants' reactions to unfamiliar persons and novel objects. Monographs of the Society for Research in Child Development, 37, 1-46. https://doi. org $/ 10.2307 / 1165685$

Campos, J. J., Emde, R. N., Gaensbauer, T., \& Henderson, C. (1975). Cardiac and behavioral interrelationships in the reactions of infants to strangers. Developmental Psychology, 11, 589-601. https://doi.org/10.1037/00121649.11.5.589

Cvencek, D., Greenwald, A. G., \& Meltzoff, A. N. (2011). Measuring implicit attitudes of 4-year-olds: The preschool implicit association test. Journal of Experimental Child Psychology, 109, 187-200. https://doi.org/10. 1016/j.jecp.2010.11.002

Cvencek, D., Greenwald, A. G., \& Meltzoff, A. N. (2016). Implicit measures for preschool children confirm selfesteem's role in maintaining a balanced identity. Journal of Experimental Social Psychology, 62, 50-57. https://doi. org/10.1016/j.jesp.2015.09.015

Cvencek, D., Meltzoff, A. N., \& Greenwald, A. G. (2011). Math-gender stereotypes in elementary school children. Child Development, 82, 766-779. https://doi.org/10. 1111/j.1467-8624.2010.01529.x

Danziger, S., \& Ward, R. (2010). Language changes implicit associations between ethnic groups and evaluation in bilinguals. Psychological Science, 21, 799-800. https:/ / doi. org/10.1177/0956797610371344 
Dasgupta, N., \& Greenwald, A. G. (2001). On the malleability of automatic attitudes: Combating automatic prejudice with images of admired and disliked individuals. Journal of Personality and Social Psychology, 81, 800814. https:/ / doi.org/10.1037/0022-3514.81.5.800

Devine, P. G., Forscher, P. S., Austin, A. J., \& Cox, W. T. (2012). Long-term reduction in implicit race bias: A prejudice habit-breaking intervention. Journal of Experimental Social Psychology, 48, 1267-1278. https://doi. org/10.1016/j.jesp.2012.06.003

Dovidio, J. F., Kawakami, K., \& Gaertner, S. L. (2002). Implicit and explicit prejudice and interracial interaction. Journal of Personality and Social Psychology, 82, 6268. https://doi.org/10.1037/0022-3514.82.1.62

Dunham, Y., Baron, A. S., \& Banaji, M. R. (2006). From American city to Japanese village: A cross-cultural investigation of implicit race attitudes. Child Development, 77, 1268-1281. https://doi.org/10.1111/j.14678624.2006.00933.x

Dunham, Y., Baron, A. S., \& Banaji, M. R. (2008). The development of implicit intergroup cognition. Trends in Cognitive Sciences, 12, 248-253. https://doi.org/10. 1016/j.tics.2008.04.006

Dunham, Y., Baron, A. S., \& Carey, S. (2011). Consequences of "minimal" group affiliations in children. Child Development, 82, 793-811. https://doi.org/10. 1111/j.1467-8624.2011.01577.x

Dunham, Y., Chen, E. E., \& Banaji, M. R. (2013). Two signatures of implicit intergroup attitudes: Developmental invariance and early enculturation. Psychological Science, 24, 860-868. https:/ / doi.org/10.1177/0956797612463081

Dunham, Y., Stepanova, E. V., Dotsch, R., \& Todorov, A. (2015). The development of race-based perceptual categorization: Skin color dominates early category judgments. Developmental Science, 18, 469-483. https://doi. org /10.1111/desc.12228

Gawronski, B., \& Bodenhausen, G. V. (2006). Associative and propositional processes in evaluation: An integrative review of implicit and explicit attitude change. Psychological Bulletin, 132, 692-731. https://doi.org/10. 1037/0033-2909.132.5.692

Ge, L., Zhang, H., Wang, Z., Quinn, P. C., Pascalis, O., Kelly, D., \& Lee, K. (2009). Two faces of the other-race effect: Recognition and categorization of Caucasian and Chinese faces. Perception, 38, 1199-1210. https://doi. org $/ 10.1167 / 8.6 .257$

Glazerman, S., \& Dotter, D. (2016). Market signals: How do DC parents rank schools, and what does it mean for policy? (Working Paper 45). Washington, DC: Mathematica Policy Research.

Greene, R. L. (1990). Spacing effects on implicit memory tests. Journal of Experimental Psychology: Learning, Memory, and Cognition, 16, 1004-1011. https://doi.org/10. 1037/0278-7393.16.6.1004

Greenwald, A. G., \& Banaji, M. R. (1995). Implicit social cognition: Attitudes, self-esteem, and stereotypes. Psychological Review, 102, 4-27. https://doi.org/10.1037/ 0033-295X.102.1.4
Greenwald, A. G., McGhee, D. E., \& Schwartz, J. L. (1998). Measuring individual differences in implicit cognition: The implicit association test. Journal of Personality and Social Psychology, 74, 1464-1480. https://doi.org/ 10.1037/0022-3514.74.6.1464

Greenwald, A. G., Nosek, B. A., \& Banaji, M. R. (2003). Understanding and using the implicit association test: I. An improved scoring algorithm. Journal of Personality and Social Psychology, 85, 197-216. https://doi.org/10. 1037/0022-3514.85.2.197

Hardin, C. D., \& Banaji, M. R. (2013). The nature of implicit prejudice: Implications for personal and public policy. In E. Shafir (Ed.), The behavioral foundations of public policy (pp. 13-31). Princeton, NJ: Princeton University Press.

Hintzman, D. L., \& Block, R. A. (1973). Memory for the spacing of repetitions. Journal of Experimental Psychology, 99, 70-74. https:/ / doi.org/10.1037/h0034761

Hitti, A., \& Killen, M. (2015). Expectations about ethnic peer group inclusivity: The role of shared interests, group norms, and stereotypes. Child Development, 86, 1522-1537. https://doi.org/10.1111/cdev.12393

Hugenberg, K., \& Bodenhausen, G. V. (2004). Ambiguity in social categorization: The role of prejudice and facial affect in race categorization. Psychological Science, 15, 342345. https://doi.org/10.1111/j.0956-7976.2004.00680.x

Ito, T. A., Friedman, N. P., Bartholow, B. D., Correll, J., Loersch, C., Altamirano, L. J., \& Miyake, A. (2015). Toward a comprehensive understanding of executive cognitive function in implicit racial bias. Journal of Personality and Social Psychology, 108, 187-218. https://doi. org/10.1037/a0038557

Kim, H. I., \& Johnson, S. P. (2014). Detecting "infantdirectedness" in face and voice. Developmental Science, 17, 621-627. https://doi.org/10.1111/desc.12146

Kinzler, K. D., Shutts, K., DeJesus, J., \& Spelke, E. S. (2009). Accent trumps race in guiding children's social preferences. Social Cognition, 27, 623-624. https://doi. org/10.1521/soco.2009.27.4.623

Lai, C. K., Marini, M., Lehr, S. A., Cerruti, C., Shin, J. E. L., Joy-Gaba, J. A., . . Frazier,, R. S. (2014). Reducing implicit racial preferences: I. A comparative investigation of 17 interventions. Journal of Experimental Psychology: General, 143, 1765-1785. https://doi.org/10.1037/ a0036260

Lai, C. K., Skinner, A. L., Cooley, E., Murrar, S., Brauer, M., Devos, T., . . . Simon, S. (2016). Reducing implicit racial preferences: II. Intervention effectiveness across time. Journal of Experimental Psychology: General, 145, 1001-1016. https://doi.org/10.2139/ssrn.2712520

Lebrecht, S., Pierce, L. J., Tarr, M. J., \& Tanaka, J. W. (2009). Perceptual other-race training reduces implicit racial bias. PLoS ONE, 4, e4215. https://doi.org/10. 1371/journal.pone.0004215

Lee, K., Quinn, P. C., \& Heyman, G. D. (2017). Rethinking the emergence and development of implicit racial bias: A perceptual-social linkage hypothesis. In E. Turiel, N. Budwig, \& P. Zelazo (Eds.), New perspectives on 
human development (pp. 27-46). Cambridge, UK: Cambridge University Press.

Lee, K., Quinn, P. C., \& Pascalis, O. (2017). Face race processing and racial bias in early development: A perceptual-social linkage. Current Directions in Psychological Science, 26, 256-262. https://doi.org/10.1177/096372 1417690276

Linville, P. W., Fischer, G. W., \& Salovey, P. (1989). Perceived distributions of the characteristics of in-group and out-group members: Empirical evidence and a computer simulation. Journal of Personality and Social Psychology, 57, 165-188. https://doi.org/10.1037/00223514.57.2.165

Malatesta, C. Z., \& Haviland, J. M. (1982). Learning display rules: The socialization of emotion expression in infancy. Child Development, 53, 991-1003. https://doi. org $/ 10.2307 / 1129139$

Marini, M., Rubichi, S., \& Sartori, G. (2012). The role of self-involvement in shifting IAT effects. Experimental Psychology, 59, 348-354. https://doi.org/10.1027/16183169/a000163

McGugin, R. W., Tanaka, J. W., Lebrecht, S., Tarr, M. J., \& Gauthier, I. (2011). Race-specific perceptual discrimination improvement following short individuation training with faces. Cognitive Science, 35, 330-347. https://doi.org/10.1111/j.1551-6709.2010.01148.x

Neto, F., da Conceiçao Pinto, M., \& Mullet, E. (2016). Can music reduce anti-dark-skin prejudice? A test of a cross-cultural musical education programme. Psychology of Music, 44, 388-398. https://doi.org/10.1177/ 0305735614568882

Nosek, B. A., Greenwald, A. G., \& Banaji, M. R. (2007). The implicit association test at age 7: A methodological and conceptual review. In J. A. Bargh (Ed.), Social psychology and the unconscious: The automaticity of higher mental processes (pp. 265-292). New York, NY: Psychology Press.

Olson, M. A., \& Fazio, R. H. (2006). Reducing automatically activated racial prejudice through implicit evaluative conditioning. Personality and Social Psychology Bulletin, 32, 421-433. https://doi.org/10.1177/ 0146167205284004

Pearson, A. R., Dovidio, J. F., \& Gaertner, S. L. (2009). The nature of contemporary prejudice: Insights from aversive racism. Social and Personality Psychology Compass, 3, 314-338. https://doi.org/10.1111/j.1751-9004. 2009.00183.x

Pettigrew, T. F., \& Tropp, L. R. (2006). A meta-analytic test of intergroup contact theory. Journal of Personality and Social Psychology, 90, 751-783. https://doi.org/10. 1037/0022-3514.90.5.751

Prestwich, A., Kenworthy, J. B., Wilson, M., \& Kwan-Tat, N. (2008). Differential relations between two types of contact and implicit and explicit racial attitudes. British Journal of Social Psychology, 47, 575-588. https://doi. org /10.1348/014466607X267470

Qian, K. M., Heyman, G. D., Quinn, P. C., Messi, F. A., $\mathrm{Fu}$, G., \& Lee, K. (2016). Implicit racial biases in preschool children and adults from Asia and Africa. Child Development, 87, 285-296. https://doi.org/10. 1111/cdev.12442

Qian, K. M., Quinn, P. C., Heyman, G. D., Pascalis, O., $\mathrm{Fu}$, G., \& Lee, K. (2017). Perceptual individuation training (but not mere exposure) reduces implicit racial bias in preschool children. Developmental Psychology, 53, 845-859. https://doi.org/10.1037/ dev0000290

Quinn, P. C., Anzures, G., Lee, K., Pascalis, O., Slater, A., \& Tanaka, J. W. (2013). On the developmental origins of differential responding to social category information. In M. R. Banaji \& S. A. Gelman (Eds.), Navigating the social world: What infants, children, and other species can teach us (pp. 286-291). New York, NY: Oxford University Press.

Quinn, P. C., Lee, K., Pascalis, O., \& Tanaka, J. W. (2016). Narrowing in categorical responding to other-race face classes by infants. Developmental Science, 19, 362-371. https://doi.org/10.1111/desc.12301

Raabe, T., \& Beelmann, A. (2011). Development of ethnic, racial, and national prejudice in childhood and adolescence: A multinational meta-analysis of age differences. Child Development, 82, 1715-1737. https://doi.org/10. 1111/j.1467-8624.2011.01668.x

Rudman, L. A., Ashmore, R. D., \& Gary, M. L. (2001). "Unlearning" automatic biases: The malleability of implicit prejudice and stereotypes. Journal of Personality and Social Psychology, 81, 856-868. https://doi.org/10. 1037/0022-3514.81.5.856

Rutland, A., Hitti, A., Mulvey, K. L., Abrams, D., \& Killen, M. (2015). When does the in-group like the outgroup? Bias among children as a function of group norms. Psychological Science, 26, 834-842. https://doi. org $/ 10.1177 / 0956797615572758$

Shook, N. J., \& Fazio, R. H. (2008). Interracial roommate relationships: An experimental field test of the contact hypothesis. Psychological Science, 19, 717-723. https://d oi.org/10.1111/j.1467-9280.2008.02147.x

Tajfel, H., \& Turner, J. C. (1979). An integrative theory of intergroup conflict. In W. G. Austin \& S. Worchel (Eds.), The social psychology of intergroup relations (pp. 33-47). Monterey, CA: Brooks/Cole.

Thomas, S., Burton Smith, R., \& Ball, P. (2007). Implicit attitudes in very young children: An adaptation of the IAT. Current Research in Social Psychology, 13, 75-85.

Trainor, L. J., Austin, C. M., \& Desjardins, R. N. (2000). Is infant-directed speech prosody a result of the vocal expression of emotion? Psychological Science, 11, 188195. https:// doi.org/10.1111/1467-9280.00240

Turner, J. C., \& Reynolds, K. J. (2010). The story of social identity. In T. Postmes \& N. Branscombe (Eds.), Rediscovering social identity: Core sources (pp. 13-32). New York, NY: Psychology Press.

Xiao, W. S., Fu, G., Quinn, P. C., Qin, J., Tanaka, J. W., Pascalis, O., \& Lee, K. (2015). Individuation training with other-race faces reduces preschoolers' 
implicit racial bias: A link between perceptual and social representation of faces in children. Developmental Science, 18, 655-663. https://doi.org/10.1111/desc. 12241

Xiao, N. G., Quinn, P. C., Liu, S., Ge, L., Pascalis, O., \& Lee, K. (2017). Older but not younger infants associate own-race faces with happy music and other-race faces with sad music. Developmental Science. https://doi.org/ $10.1111 /$ desc. 12537
Xiao, N. G., Wu, R., Quinn, P. C., Liu, S., Tummeltshammer, K. S., Kirkham, N. Z., . . . Lee, K. (2017). Infants rely more on gaze cues from own-race than other-race adults for learning under uncertainty. Child Development. https://doi.org/10.1111/cdev.12798

Zebrowitz, L. A., Bronstad, P. M., \& Lee, H. K. (2007). The contribution of face familiarity to ingroup favoritism and stereotyping. Social Cognition, 25, 306-338. https://doi.org/10.1521/soco.2007.25.2.306 